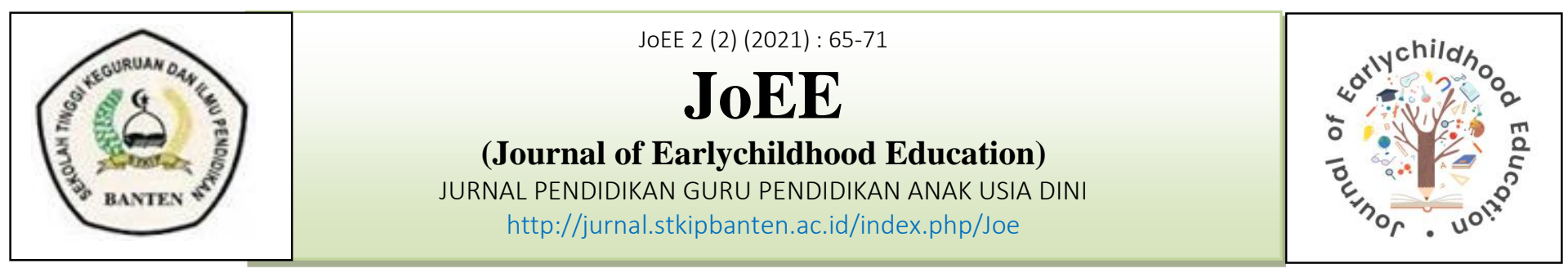

\title{
PENGGUNAAN PERMAINAN ULAR TANGGA UNTUK MENINGKATKAN PERKEMBANGAN MOTORIK KASAR ANAK USIA DINI
}

\author{
Alvan Hazhari ${ }^{1}$, Larasati Nur Indah Prawesti ${ }^{2}$, dan Nurmilah ${ }^{3}$ \\ ${ }^{1}$ Sekolah Tinggi Keguruan dan Ilmu Pendidikan Banten \\ ${ }^{2}$ Sekolah Tinggi Keguruan dan Ilmu Pendidikan Banten \\ ${ }^{3}$ Mahasiswa Pendidikan Guru Pendidikan Anak Usia Dini \\ Penulis Korespondensi: hazharialvan2193@gmail.com ${ }^{1}$, iiazzprawesti@gmail.com², \\ nurmilahmilah71@gmail.com ${ }^{3}$ \\ Artikel: Perkembangan Motorik Kasar Anak Usia Dini \\ Penerima: Juli 2021 Diterima: Agustus $2021 \quad$ Dipublikasikan: September 2021
}

\begin{abstract}
Snakes and ladders game is a game played by 2 or more people, gross motor skills are the ability to move the body using large muscles. This study aims to improve the gross motor development of early childhood in group B Al-Firmansyah Cinkande Kindergarten through the game of snakes and ladders. This research is a classroom action research (CAR), with the research subjects being group B children, totaling 10 children consisting of 6 boys and 4 girls, while the data collection method used was observation with an assessment instrument. Based on the results of the study showed that the method of playing the game of snakes and ladders can improve gross motor development of early childhood. Initial development before the action showed the number of $60 \%$ of the presentation of children with BB criteria (Not Developed) after the action in cycle I had increased by showing the number of $40 \%$ of the percentage of children with BSH criteria (Developing As Expected) after treatment in cycle II had increased with a total of $70 \%$ of the percentage of children with BSB criteria (Very Good Development). The conclusion shows that the percentage of gross motoric development of children in group $B$ who completes the school KKM according to the success indicators is $75 \%$.
\end{abstract}

Keywords: Gross Motor Development, Snake Ladder Game Median of early childhood

\section{ABSTRAK}

Permainan ular tangga adalah permaianan yang dimainkan 2 orang atau lebih, motorik kasar adalah kemampuan gerak tubuh yang menggunakan otot-otot besar. Penelitian ini bertujuan untuk meningkatkan perkembangan motorik kasar anak usia dini di kelompok B TK Al-Firmansyah Cinkande melalui permainan ular tangga. Penelitian ini merupakan penelitian tindakan kelas ( PTK ), dengan subjek penelitian yaitu anak kelompok B yang berjumlah 10 anak yang terdiri dari 6 anak laki-laki dan 4 anak prempuan, sedangkan metode pengumpulan data yang digunakan adalah observasi dengan instrumen penilaian. 
Alvan Hazhari, Larasati Nur Indah Prawesti, dan Nurmilah. Penggunaan Permainan Ular Tangga Untu Meningkatkan Perkembangan Motorik Kasar Anak Usia Dini Kelompok B di TK AlFirmansyah Cikande

Berdasarkan hasil penelitian menunjukan bahwa metode bermain permainan ular tangga dapat meningkatkan perkembangan motorik kasar anak usia dini. Perkembangan awal sebelum tindakan menunjukan jumlah $60 \%$ dari presentasi anak dengan kriteria BB (Belum Berkembang) setelah dilakukan tindakan pada siklus I mengalami peningkatan dengan menunjukan jumlah $40 \%$ dari presentase anak dengan kriterian BSH ( Berkembang Sesuai Harapan ) setelah dilakukan tinfakan pada siklus II mengalami peningkatan dengan jumlah $70 \%$ dari presentase anak dengan kriteria BSB ( Berkembangan Sangat Baik ). Kesimpulan menjukan bahwa presentase perkembangan motorik kasar anak di kelompok B yang mencapai tuntas dengan KKM sekolah sesuai indikator keberhasilan sebesar 75\%.

Kata Kunci: Perkembangan Motorik Kasar, Media Permaian Ular Tangga. Anak Usia Dini

\section{PENDAHULUAN}

Mengembangkan kemampuan fisik motorik kasar anak usia dini, stimulasi sangat penting untuk mengiptimalkan kemampuan otot-otot besar pada anak usia dini, karena fisik motorik kasar berhubungan dengan kemampuan otot-otot besar. Oleh karena itu, masa anak usia dini merupakan masa yang sangat penting dalam mengembangkan kemampuan motorik kasar anak.

Apabila pada masa anak perkembangan motorik kasar anak tidak memadai, maka kemungkinan besar anak mengalami gangguan fungsi otot-karena sebab-sebab tertentu, akan tetapi kemampuan motorik kasar setiap anak berbeda, hal ini dipengaruhi oleh pembawaan dan stimulasi yang diperoleh anak.Untuk meningkatkan keterampilan motorik kasar anak diarahkan untuk melakukan kegiatan yang menggerakan seluruh tubuh.
Menurut Siti Aisyah (2020) Motorik kasar adalah keterampilan yang melibatkan gerakan seluruh tubuh, kegiatan yang menggunakan otot inti seperti lengan dan kaki, aktivitas dari motorik kasar dalam indikator penelitian ini berupa berjalan, melompat dan berlari.

Berdasarkan hasil observasi awal yang dilakukan peneliti di TK AlFirmansyah Cikande khusunya kelompok B menunjukan bahwa masih belum berkembang kemampuan fisik motorik kasar pada anak, permasalahan yang dihadapi anak didik kelompok B TK AlFirmansyah Cikande adalah media permainan yang monoton dan yang digunakan kurang bervariasi sehingga kurang menarik bagi anak.

Hal ini dilihat dari hasil belajar anak kelompok B di TK Al-Firmansyah Cikande yang berjumlah 10 anak menunjukan bahwa kemampuan belum berkembang (BB) sebanyak 6 anak, mulai berkembang (MB) sebanyak 2 anak, 
berkembnag sesuai harapan (BSH) sebanyak 1 anak dan berkembang sagat baik (BSB) sebanyak 1 anak. Sehingga dapat di peroleh presentase $80 \%$ (8 anak) belum mampu mengoptimalkan kemampuan motorik kasar dan 20\% (2 anak) mampu melakukan perkembangan motorik kasar.

Dari hasil data awal menunjukan bahwa masih rendahnya kegiatan pembelajaran pada motorik kasar. Oleh karena itu, guru sebagai pendidik dapat mencari metode yang tepat dalam kegiatan bermain dan dapat melakukan inovasi yang menarik dalam bermain.

Menurut Montolalu (2014: 10) Permainan adalah suatu yang digunakan untuk bermain (sebuah mainan) sebuah barang atau sesuatu yang pada umumnya digunakan untuk hiburan atau kesenangan dan sering kali digunakan untu pendidikan.

Menurut M. Thobroni dan Fairuzal Mumtaz (2011: 9) Bermain adalah dunia anak ketika bermain. Terdapat salah satu permainan yang dapat meningkatkan kemampuan motorik kasar yaitu melalui permainan ular tangga.

Menurut Melsi (2015: 10) Permainan ular tangga adalah permainan papan untuk dimainkan oleh 2 orang atau lebih, papan permainan di bagi dalam kotak -kotak kecol dan dibeberapa kotak digambar sejumlah " tangga " dan " ular " yang menghubungkan dengan kotak lain. (C) 2021, JoEE, Jurnal of Early Childhood. PGPAUD e-ISSN: 2775-7870
Menurut Ratnaningsih (2014) Permainan ular tangga adalah permainan yang digunakan dadu untuk menentukan berapa langkah yang harus dijalani bidak.

Tujuan yang ingin dicapai pada penelitian ini adalan peneliti bertujuan untuk mengetahui penggunaan permainnan ular tangga untuk meningkatkan perkembnagan motorik kasar bagi anak usia dini kelompok $\mathrm{B}$ di TK AlFirmansyah Cikande.

\section{METODE}

Penelitian ini dilaksanakan di TK AlFirmansyah Cikande. Subjek penelitian ini adalah anak kelompokm B yng berjumlah 10 anak yang terdiri dari 6 anak laki-laki dan 4 anak prempuan, berdasarkan kemampuan motorik kasar anak masih cukup rendah dengan kondisi ini yang diperlukan media pembelajaran yang menarik bagi anak untuk meningkatkan kemampuan motorik kasarnya.

Penelitian ini dirancang dengan rancangan penelitian tindakan kelas (PTK) Menurut Igak Wardahani dan Kuswaya (2014: 14) Penelitian tindakan kelas adalah suatu jenis penelitian yang bertujuan untuk mengatasi masalah pembelajran yang terjadi pada latar penelitian (kelas) dengan melakukan perbaikan terhadap sistem, cara kerja proses, isi, kompetensi atau sisuasi.

Model perencanaan penelitian tindakan kelas yang digunakan mengacu 
Alvan Hazhari, Larasati Nur Indah Prawesti, dan Nurmilah. Penggunaan Permainan Ular Tangga Untu Meningkatkan Perkembangan Motorik Kasar Anak Usia Dini Kelompok B di TK AlFirmansyah Cikande

pada rancangan model kemmis dan target dengan 2 siklus masing -masing siklus terdiri dari 4 tahapan :

\section{Perencanaan ( Planning )}

Rencana sebelum mengadakan penelitian menyusun rumusan masalah dan membuat rencana tindakan termasuk didalamnya instrument penelitian dan perangkat pembelajaran.

\section{Pelaksanaan ( Acting )}

Tindakan merupaka tindakan pelaksanaan pembelajaran dikelas atau pengamatan tindakan yang dilakukan oleh peneliti sebagai upaya membangaun pemahaman konsep anak setra mengamati hasil atau dampak dari diterapkan nya tindakan tersebut.

\section{Pengamatan ( Observing )}

Pengamatan merupakan pengamatan yang dilakukan oleh peneliti, pada bagian pengamatan dilakuka perekaman data yang meliputi proses dan hasil dari pelaksanaan kegiatan. Pengamatan dilakukan pada waktu bersamaan, tujuan dilakukannya pengamatan adalah untuk mengumpulkan bukti-bukti hasil tindakan yang sudah dilaksanakan agar dapat di evakuasi dan dijadikan landasan bagi peneliti dalam melakukan refleksi.

\section{Refleksi ( Reflecting )}

Refleksi,pada tahap ini peneliti bersama guru mengambil kesimpulan tentang pembelajaran yang dikembangkan (c) 2021, JoEE, Jurnal of Early Childhood. PGPAUD e-ISSN: 2775-7870 berdasarkan data yang diperoleh Meneurut Arikunto (2010: 137) adapun model PTK yang dimaksud menggambarkan adanya 4 langkah yang disajikan dalam bentuk rangkaian sebagai berikut : perencanan

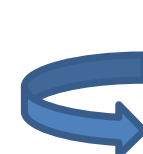

perencanaan
Siklus I

refleksi

pelaksanaa

\section{HASIL DAN PEMBAHASAN}

\section{Hasil}

Terdapat peningkatkan terhadap perkembangan motorik kasar anak usia dini pada pra tindakan mengalami BB 6 anak, pada siklus I mengalami peningkatan BSH 4 anak sedangkan pada siklus II mengalami peningkatan BSB 7 anak. Seghingga Permainan Ular Tangga dapat Meningkatkan Perkembangan Motorik Kasar Anak Usia Dini Kelompok B di TK Al-Firmansyah Cikande dengan baik sehingga telah mencapai indikator keberhasilan.

Berikut adalah tebel Rekapitulasi Hasil Penilitian Akhir Obervasi Perkembangan Anak dalam permainan ular tangga terhadap perkembangan motoric kasar 
TABEL

Rekapitulasi Hasil Penilitian Akhir

Obervasi Perkembangan Anak

\begin{tabular}{|c|c|c|c|c|c|c|c|}
\hline \multirow[t]{3}{*}{ No } & \multirow{3}{*}{$\begin{array}{l}\text { Hasi } \\
1 \mathrm{PP}\end{array}$} & \multicolumn{6}{|c|}{ Keterangan } \\
\hline & & \multicolumn{2}{|c|}{$\begin{array}{c}\text { Pra } \\
\text { Tindakan }\end{array}$} & \multicolumn{2}{|c|}{ Siklus I } & \multicolumn{2}{|c|}{ Siklus II } \\
\hline & & $\mathrm{Ak}$ & Pres & $\mathrm{Ak}$ & $\begin{array}{l}\text { Pres } \\
\text { en }\end{array}$ & $\mathrm{Ak}$ & Pres \\
\hline 1 & $\mathrm{BB}$ & 6 & $60 \%$ & 3 & $30 \%$ & 0 & $0 \%$ \\
\hline 2 & $\mathrm{MB}$ & 2 & $20 \%$ & 2 & $20 \%$ & 1 & $10 \%$ \\
\hline 3 & $\mathrm{BSH}$ & 1 & $10 \%$ & 4 & $40 \%$ & 2 & $20 \%$ \\
\hline 4 & BSB & 1 & $10 \%$ & 1 & $10 \%$ & 7 & $70 \%$ \\
\hline \multicolumn{2}{|c|}{ Jumlah } & $\begin{array}{l}10 \\
\mathrm{Ak}\end{array}$ & $\begin{array}{l}100 \\
\%\end{array}$ & $\begin{array}{l}10 \\
\mathrm{Ak}\end{array}$ & $\begin{array}{l}100 \\
\%\end{array}$ & $\begin{array}{l}10 \\
\mathrm{Ak}\end{array}$ & $\begin{array}{l}100 \\
\%\end{array}$ \\
\hline
\end{tabular}

Deskripsi anak yang sudah tuntas adalah anak yang mencapai indikator keberhasilaan, seperti melompat, berjaln dan berlari dan kriteria tuntas yaitu $\mathrm{BSH}$ dan BSB sedangkan kriteria belum tuntas yaitu BB dan MB.

\section{Pembahasan}

\section{Siklus I}

Dari hasil analisa perhitungan perkembangan motorik kasar anak pada siklus I masih pada katagori kurang meningkat yaitu dengan presentase ketuntasan belajar 50\% kurang dari kriteria ketuntasan minimal 75\%. Hal ini disebabkan karena anak baru mengetahui permainan ular tangga yang digunakan guru dalam pembelajaran sehingga anak masih bingung cara permainannya dan anak masih perlu berulang-ulang untuk memahaminya.

(C) 2021, JoEE, Jurnal of Early Childhood. PGPAUD e-ISSN: 2775-7870
Dari hasil data tersebut dapat diperoleh presentase ketuntasan belajar anak dalam kemampuan motorik kasar melalui permainan ular tangga pada siklus I mencapai 50\%. Maka kegiatan pembelajaran ini dinilai belum tuntas dan harus diadakan perbaikan pada siklus selanjutnya.

\section{Siklus II}

Berdasarkan hasil analisa perhitungan perkembangan motorik kasar anak pada siklus II berada pada katagori meningkat yaitu dengan presentase ketuntasan belajar perkembangan penjumlahan anak sebesar 90\%. Lebih dari kriteria ketuntasan minimal yang telah ditetapkan $75 \%$ sehingga tidak perlu dilakukan pelaksanaan siklus III ini telah berhasil mencapai ketuntasan minimal yang telah ditentukan.

Dari data tersebut diperoleh presentase ketuntasan belajar anak dalam perkembangan motorik kasar anak melalui permainan ular tangga pada siklus II adalah mencapai 90\% maka kegiatan pembelajaran ini sudah tuntas dan tidak perlu dilakukan perbaikan pada siklus selanjutnya.

\section{PENUTUP}

\section{Kesimpulan}

Berdasarkan hasi penelitian dan pembahasan dapat diambil kesimpulan bahwa permaina ular tangga dapat meningkatkan perkembangan motorik 
Alvan Hazhari, Larasati Nur Indah Prawesti, dan Nurmilah. Penggunaan Permainan Ular Tangga Untu Meningkatkan Perkembangan Motorik Kasar Anak Usia Dini Kelompok B di TK AlFirmansyah Cikande

kasar anak usia dini kelompok B di TK AlFirmansyah, hal ini dapat dibuktikan dengan meningkatnya perkembangan motorik kasar anak presentasi awal pra tindakan menunjukan presentase anak BB 6 anak, MB 3 anak, BSH 1 anak dan BSB 1 anak mengalami peningkatan pada siklus I BB 3 anak, MB 2 anak, BSH 4 anak dan BSB 1 anak kemudian pada siklus II mengalami peningkatan perkembangan motorik kasar anak usia dini BB 0\%, MB 10\% dari 1 ansk, BSH $20 \%$ dari 2 anak didik dan BSB $70 \%$ dari 7 anak didik, telah terlaksan dengan baik sehingga indikator keberhasilan dapat dicapai.

\section{Saran}

Berdasarkan penelitian tindakan kelas (PTK) untuk meningkatkan perkembangan motorik kasar anak usia dini mak ada beberapa saran untuk meningkatkan perkembangan motorik kasar anak

\section{Bagi Guru}

Sebaiknya lebih kreatif dan inovatif dalam melakukan kegiatan agar lebih bermakna dan menarik minat anak untuk ikut aktif dalam kegiatan

2. Bagi Anak

Anak harus ditingkatkan latihanya dan mengulang-ulang kembali permainan ular tangga yang telah diajarkan oleh guruagar dapat meningkatkan motorik kasar anak.

(C) 2021, JoEE, Jurnal of Early Childhood. PGPAUD e-ISSN: 2775-7870

\section{Bagi Sekolah}

Perlu diadakan pertemuan dengan orang tua anak untuk menjalin kerjasama dalam mendidik dan membimbing anak dan memberikan fasilitas sarana dan pasarna yang mendukung anak dalam proses belajar mengajar untuk meningkatkan motorik kasar anak usia dini.

4. Bagi Peneliti

Peneliti berharap dapat menambah wawasan peneliti akan kegiatan dalam pembelajaran khususnya dalam meningkatkan perkembangan motorik kasar anak usia dini dan berharap dapat memberi manfaat dan sebagai kajian yang relevan dalam penulisan karya ilmiyah lainnya.

\section{DAFTAR PUSTAKA}

Amirul Huda, Fakthan. 2017. Pengertian Perkembangan Media Permainan Ular Tangga. Stkip Kusuma Negara.

Dita Purbo Anggarini. 2018. Meningkatkan Kemampuan Motorik Kasar Melalui Permainan UlarTangga Kreatif Kelompok $B$ $P A U D$. Universitas Nusantara PGRI Kediri.

Hazhari, Alvan. 2020. "Meningkatkan Kemampuan Motorik Kasar Anak Usia Dini Melalui Gerakdan Lagu, Bernyanyi Dengan Riang", jurnal, stkipbanten.

Khifdhotuz, Zuhriyyah, 2019. Peningkatan Keterampilan Melompat Melalui 
Permainan Modifikasi Puzzle Kata Pintar Kelompok A TK Brilliant Waru.

Universitas Islam Negri Sunan Ampel Surabaya. Masitoh, 2011. Strategi Pembelajaran: Universitas Terbuka.

Montolalu, (dkk). 2014. Bermain dan Permainan Anak. Universitas Terbuka

Muhamad iza dan Ayu Swaliana. 2018. Perkembangan Kompetensi Motorik Kasar Anak di PAUD, Jurnal AsSalam, 2 (3) September-Desember.

Muhammad Hasbi dkk, 2020. Penting Bermain Bagi Anak Usia Dini: Jalan Jendral Sudirman, Gedung E It.7, Senayan Jakarta 10270.

Siti Istiqomah, 2018. Penerapan Metode Bermain Melalui Permainan Ular Tangga Dalam Mengembangkan Kognitif Anak Usia 5-6 Tahun di PAUD Sriwijaya Lampung Timur . Lampung. Universitas Islam Negri Raden Intan .

Sofiyan, Nuning. 2012. Upaya mengembangkan motoric kasar Melalui Bermain. Skripsi: Universitas PGRI Yogyakarta .

Sujiono, Bambang (dkk). 2014. Metode Perkembangan Fisik .Universitas Terbuka.PT. Alpha Aksara

Tatminingsih, Sri. 2014. Perkembangan dan Konsep Dasar Pengembangan Anak Usia Dini PT.Gramedi. 